\title{
Differences in the impact of harmonic distortion due to the installation of electronic load controller in self-excited induction generator and synchronous generator
}

\author{
Refdinal Nazir ${ }^{1}$, Syafii $^{2}$, Andi Pawawoi ${ }^{3}$, Fajril Akbar ${ }^{4}$, Axel Dorinza ${ }^{5}$ \\ 1,2,3,5 Department of Electrical Engineering, Andalas University, Indonesia \\ ${ }^{4}$ Department of Information System, Andalas University, Indonesia
}

\begin{tabular}{l} 
Article Info \\
\hline Article history: \\
Received Aug 20, 2018 \\
Revised Oct 20, 2018 \\
Accepted Dec 6, 2018 \\
\hline Keywords: \\
Electronic load controller \\
Generator \\
Hormonic distortion \\
Self-excited induction \\
Synchronous generator \\
THD
\end{tabular}

THD

\begin{abstract}
In general, the application of Self-Excited Induction Generator (SEIG) or Synchronous Generator (SG) on the Stand-Alone Micro Hydel Power Plant (MHPP) is equipped with Electronic Load Controller (ELC) to control generator output during variations in consumer load. One type of ELC that is cheap and rigid developed today is the ELC, which is constructed by the uncontrolled bridge rectifier with DC Chopper. Based on the operational concept, basically this type of ELC can be implemented on both SEIG and SG, but both of these generators will have a different harmonic distortion effect on the output and its load. This paper examines the differences in the effects of harmonic distortions due to ELC installation on SEIG and SG. The initial stage of this study was to design the ELC developed. Then, the harmonic distortion response due to the installation of ELC on SEIG and SG is tested, which includes harmonic distortion in: stator current, PCC voltage, and consumer load current. THD I (Current Total Harmonic Distortion) stator current at SEIG with ELC has shown an average value smaller than the THD stator current in SG with ELC. Likewise, the THDv (Voltage Total Harmonic Distortion) value of PCC voltage and THDI value of the current consumer load on SEIG equipped with ELC has been shown to be smaller than the THDV value of PCC voltage and $\mathrm{THD}_{\mathrm{I}}$ value of the current consumer load on SG equipped with ELC. The effects of harmonic distortions due to the installation of ELCs that developed in this study on SEIG is still within the permitted limits, while on the $\mathrm{SG}$, the harmonic distortion reduction is needed at the generator output.
\end{abstract}

Copyright (c) 2019 Institute of Advanced Engineering and Science. All rights reserved.

\author{
Corresponding Author: \\ Refdinal Nazir, \\ Department of Electrical Engineering, \\ Andalas University, \\ Jalan Dr. Mohammad Hatta Padang 25163, Indonesia. \\ Email: refdinalnazir@eng.unand.ac.id
}

\section{INTRODUCTION}

In a number of rural areas isolated in Indonesia is widely used Micro Hydel Power Plant (MHPP) as the main supplier of its electrical energy, which generally have a capacity below $50 \mathrm{~kW}$. This power plant can use synchronous generators (SG) or Self-Excited Induction Generators (SEIG). MHPP in capacity below 50 $\mathrm{kW}$ is usually designed at the minimum flow of the river stream. This allows the power plant to always get a constant input flow rate equal to the design flow, so there is no need to control the input side and the generator output power kept constant [1], [2]. While this power plant is connected to the consumer loads which always fluctuates. To keep the output variable of the power plant constant at the permitted value, a control system is needed. This appropriate control system for stand-alone MHPP is dummy loads control installed in parallel with consumer load, better known as Electronic Load Controller (ELC) [1], [2]. ELC uses the concept of active 
power balance between generator output power with consumer load \& dummy load. Based on this concept, ELC can be applied both to Self-Excited Induction Generators (SEIG) and Synchronous Generators (SG).

According to the literature [1]-[3] there are a number of types of ELC technology that have been studied and implemented. Based on the dummy load control method, ELC can be grouped into 4 types: binaryweighted switching regulation, phase-angle regulation, controlled bridge rectifier, and uncontrolled bridge rectifier with dc chopper. In binary-weighted switching regulation, some resistive load or ballast in a binaryweighted combination is used as a dummy load. The dummy load control is done through the selection of a combination of resistive or ballast that is parallel to the consumer load. The advantages of this ELC type can be minimize harmonic distortion, but are less reliable due to non-rigid construction. In phase-angle regulation ELC, dummy loads are built from a resistive load or ballast, which is equipped with an anti-parallel thyristor or triac. The dummy load is controlled through the phase-angle setting of the thyristor or triac. The disadvantage of this ELC type can generate relatively large harmonic currents, but provide a faster response than the previous ELC type against changes the consumer load. In controlled bridge rectifier ELC, the output voltage of the generator is rectified using a 3-phase rectifier bridge, which its output is connected to a resistive load. The 3 phase bridge rectifier is constructed using a thyristor, so that the output voltage can be controlled by the phase-angle. Similar to phase-angle regulation ELC, this ELC type generates a large harmonic current, but the construction is more rigid.

ELC type of uncontrolled bridge rectifier with DC Chopper was first developed by Bhim Singh, et. all. [1], [2] to control the voltage and frequency of the induction generator. This type of ELC is constructed by uncontrolled bridge 3-phase rectifier, dc chopper, a resistive load or ballast as a dummy load. The dummy load control was carried out by setting dc chopper using Pulse Wide Modulation (PWM) method. The advantages of this ELC type can minimize harmonic distortion in the generator and its construction is more rigid [3]. In addition, the battery can also be used as a dummy load so that the excess power of the generator in the condition of a lower consumer load is not discarded but stored in a battery, as has been studied by Refdinal et. al. in literature [4], [5].

Based on the concept of active power balance, basically ELC can be applied to both SEIG and SG. But both of these generators will provide different harmonic performance responses to the installation of ELC on both generators. Previous studies in the literature [6] have compared the harmonic performance response between SEIG and SG if connected with the same non-linear load. In this paper, differences in harmonic perfomance responses between SEIG and SG that installed with ELC type uncontrolled bridge rectifiers with DC Chopper as voltage controllers and generator frequencies during load variations is studied. This study included: ELC design, testing harmonic response to ELC installation on SEIG and SG, and comparison analysis between harmonic responses on SEIG and SG. The harmonic performance studied is focused more on the harmonic distortion difference from the stator current, voltage at the point of common coupling (PCC), and the current of the consumer load.

\section{DESCRIPTION OF PROPOSED SYSTEM}

\subsection{ELC as active power balance controller}

Basically, ELC acts to stabilize the voltage and frequency of the generator output by balancing the active power between the generator output power $\left(P_{\mathrm{o}}\right)$ and the consumer load $\left(P_{\mathrm{L}}\right)$. If there is a decrease in active power on the consumer load, then ELC will set the active compesation power $\left(P_{\mathrm{C}}\right)$ so that it fulfills the condition:

$$
P_{\mathrm{o}}=P_{\mathrm{L}}+P_{\mathrm{C}}
$$

while,

$$
P_{\mathrm{C}}=P_{\mathrm{d}}+P_{\text {Loss }}
$$

where, $P_{\mathrm{d}}$ is power that dissipated by dummy load, and $P_{\text {Loss }}$ is the power losses on transformers and DC chopper.

This active power balance process can be carried out by ELC both on SEIG and SG, as shown in Figure 1. The power settings dissipated into the dummy load $\left(P_{\mathrm{d}}\right)$ are excecuted by ELC, which is done by controlling the conductive period (Ton) for each period of DC Chopper switching. The method used in this control is known as the pulse width modulation method (PWM). In this method, the signal from the controller is converted by the PWM driver to the PWM pulse form. MOSFET driver works amplifying the PWM signal that is inputted to the MOSFET gate. In addition, the MOSFET driver also functions as a ground separator 
between the control circuit and the power circuit. The MOSFET from Chopper will be conductive according to the PWM signal pattern that is inputted to its gate.

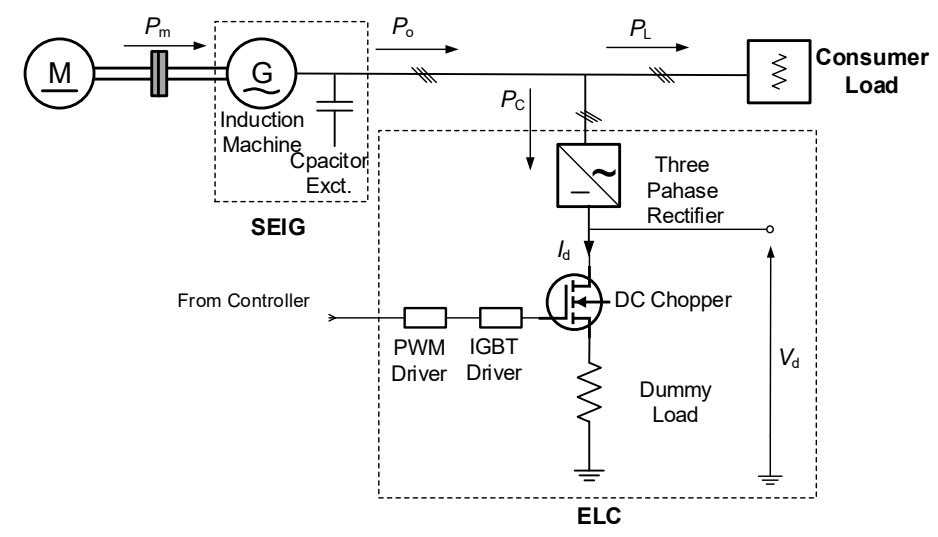

a. SEIG with ELC

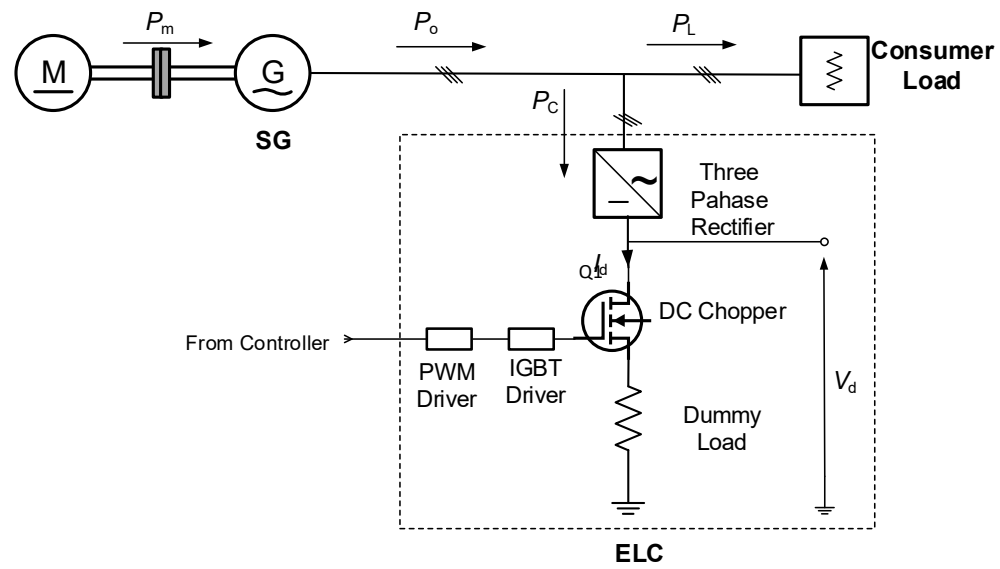

b. SEIG with EL

Figure 1. The different of configuration systems for SEIG and SG with ELC

The average dc current value that flows to the dummy load $I_{\mathrm{d}}$ is solved by the following (3):

$$
I_{\mathrm{d}}=\frac{T_{\mathrm{on}}}{T} I
$$

Where,

$$
\begin{aligned}
& I=\frac{V_{\mathrm{d}}}{R_{\mathrm{d}}}=\text { the maximum dc current that flows to the dummy load }\left(R_{\mathrm{d}}\right) \\
& T_{\text {on }}=\text { MOSFET conduction period in one period } \\
& T=\text { PWM pulse period or MOSFET conduction period } \\
& \delta(\%)=\frac{T_{\text {on }}}{T} \times 100=\text { duty cycle }
\end{aligned}
$$
relationship:

The amount of power that ELC dissipates to the dummy load can be calculated from the following 


$$
P_{\mathrm{d}}=I_{\mathrm{d}} V_{\mathrm{d}}=\delta I V_{\mathrm{d}}
$$

As shown by (4), the power dissipated into the dummy load is directly proportional to the value of the duty cycle $(\delta)$.

\subsection{ELC as harmonic current sources}

As discussed in the previous section, ELC is constructed from non-linear components consisting of diodes and MOSFET. These non-linear components cause harmonic currents to be generated by the ELC. In the power plant, ELC is a harmonic current source, while generators and consumer loads are targets of harmonic current propagation. If the consumer load contains a non-linear load then the consumer load is also a harmonic current source, but in this study is focused on ELC analysis as a harmonic current source while the consumer load is assumed to be a pure linear load.

Harmonic currents will flow from ELC as a harmonic current source to both the generator windings and the consumer load, as shown in Figure 2. However, harmonic currents will be more likely to flow to the source because they have a smaller impedance than the load [7]. The difference between the equivalent circuit between SEIG and SG is shown in Figure 2 will give a different response to generation and propagation harmonic current. SG with synchronous impedance $\boldsymbol{Z}_{\mathrm{s}}$ that is connected ini series will reduce the high-order harmonic current flowing to the stator windings.

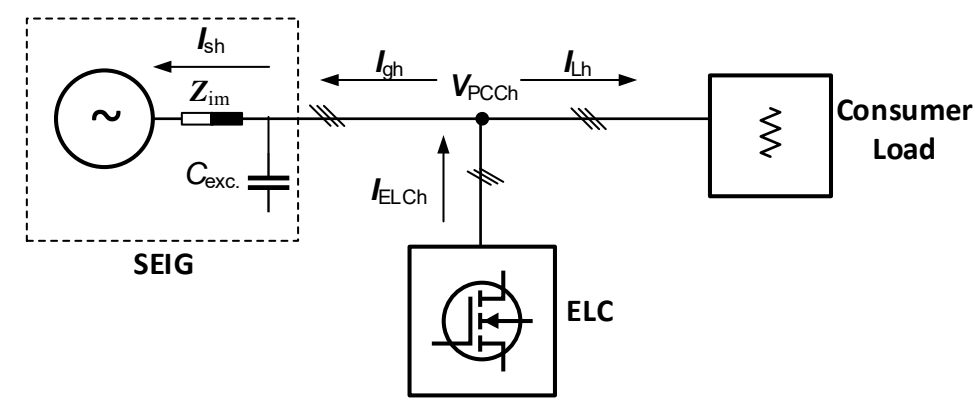

a. ELC connected to SEIG

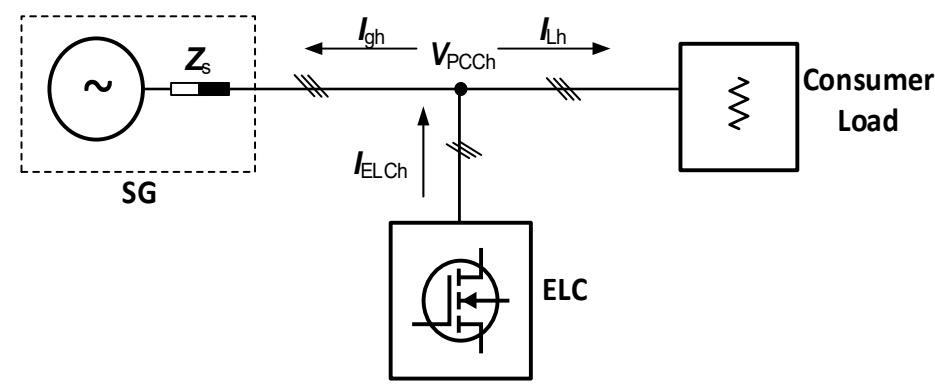

b. ELC connected to SG

Figure 2. The connection ELC as harmonics current source to SEIG and SG

Whereas in SEIG, the excitation capacitor connected in parallel can block the high order harmonic current to flow to the stator windings. The harmonic voltage on PCC $\left(V_{\mathrm{PCCh}}\right)$ will be determined by the voltage drop due to the harmonic current in the stator windings [8].

$$
\boldsymbol{V}_{\mathrm{PCCh}}=\boldsymbol{E}_{\mathrm{h}}-\boldsymbol{I}_{\mathrm{sh}} \boldsymbol{Z}_{\mathrm{im}}
$$

$E_{\mathrm{h}}$ is an induction voltage, which contains an innate harmonic component due to imperfect construction of the generator. 


\section{DESIGN AND EXPERIMENTAL SET UP}

ELC is built by the following components: three-phase bridge uncontrolled rectifier, DC filter, DC Chopper MOSFET, and dummy load. In addition, if the ELC system voltage is greater than the voltage rating of the uncontrolled rectifier and the dc chopper, then it requires three- phase step-down transformers to decrease the generator terminal voltage, as shown in Figure 3. ELC is also equipped with an Arduino microcontroller as a PWM signal generator, and the mosfet driver as a PWM signal amplifier that inputted to the MOSFET gate.

In this study, three-phase step-down transformers $1.5 \mathrm{KVA}, 220 \mathrm{~V} / 110 \mathrm{~V}, \mathrm{Y}-\mathrm{Y}$ connection is used, so that the $V_{\mathrm{LN}}$ per-phase voltage inputted to the three-phase uncontrolled rectifier is 110 Volts. The average dc voltage generated by this rectifier is [9]:

$$
V_{\text {mean }}(\mathrm{dc})=\frac{3 \sqrt{6}}{\pi} V_{L N}
$$

For $V_{\mathrm{LN}}=110$ Volt, then:

$$
V_{\text {mean }}(\mathrm{dc})=\frac{3 \sqrt{6}}{\pi} 110=257.30 \text { Volt }
$$

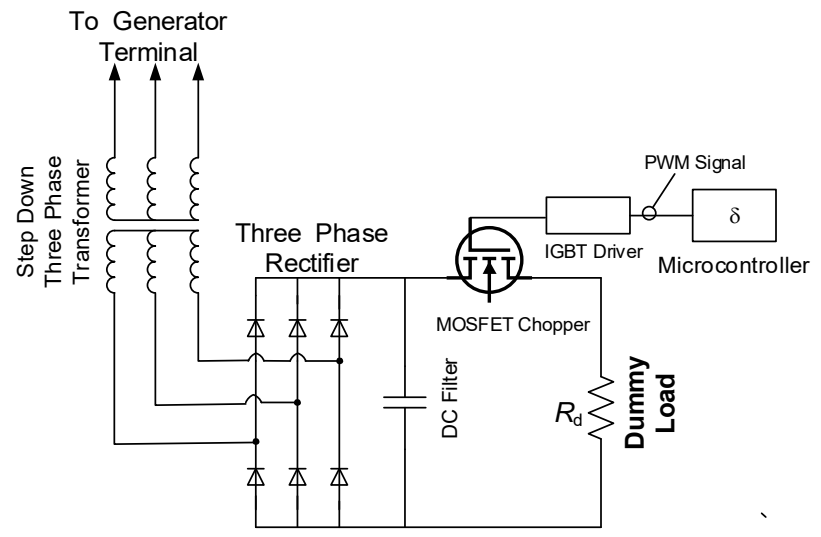

Figure 3. Schematic diagram of the ELC devoloped

The peak voltage $V_{\text {peak }}$ can be solved from the following (8):

$$
V_{\text {peak }}=\sqrt{2} V_{\text {mean }}(d c)=\sqrt{2} \times 257,430 \mathrm{Vdt}=364.01 \mathrm{Volt}
$$

In this design, the maximum power flowed to ELC (dummy load) is set to 720 Watts, so the maximum AC current flowing on the rectifier input side is:

$$
I_{\mathrm{ac}}=\frac{P}{3 V_{\mathrm{LV}}}=\frac{720}{3 \times 110}=2.18 \text { Ampere }
$$

The maximum Crest Factor $(\mathrm{CF})$ for the input current of three-phase uncontrolled rectifier with dc filter is 2.0 [9]. So that the input peak current can be calculated by the following (10):

$$
I_{\text {peak }}=2.0 I_{\mathrm{ac}}=4.36 \mathrm{~A}
$$

The magnitude of peak current and peak voltage given by $(6 \& 8)$ is the basic reference for the capacity selection of rectifier and MOSFET components used for testing. In this study, Power MOSFET IRFP460 is applied as DC Chopper component. To calculate the value of $\mathrm{Rd}$, it must be determined in advance the maximum power that is dissipated into the dummy load. In this study the maximum power that is dissipated

Int J Pow Elec \& Dri Syst, Vol. 10, No. 1, March 2019 : 104 - 116 
into the Pd dummy load is 720 Watts. So that the amount of dummy load resistance can be solved through the following (11):

$$
R_{\mathrm{d}}=\frac{V_{\mathrm{dc}}(\text { mean })^{2}}{P_{\mathrm{d}}}=\frac{(257.30)^{2}}{720}=91.95 \Omega
$$

\subsection{Experimental set up}

Figure 4 shows the experimental circuits for SEIG with ELC and SG with ELC. The both generators are driven by DC motors as the prime mover, which its rotation can be regulated using a DC regulator. SEIG used in this test are squirrel cage induction machine type, 3-phase, $1 \mathrm{~kW}, 380 \mathrm{Volt}, 50 \mathrm{~Hz}, 4$ poles, Y connection, which is connected with $3 \times 10 \mu \mathrm{F}$ excitation capacitors in delta connection. Whereas the synchronous generator applied in the test is a salient pole type, 3-phase, $1 \mathrm{kVA}, 380 \mathrm{Volt}, 50 \mathrm{~Hz}, 4$ pole, Y connection. Consumer load is designed using a combination of several incandescent light bulbs as pure resistive loads, with the capacity of the load varied as follows: $150 \mathrm{~W}, 225 \mathrm{~W}, 300 \mathrm{~W}, 375 \mathrm{~W}, 450 \mathrm{~W}, 525 \mathrm{~W}, 600 \mathrm{~W}$, and $675 \mathrm{~W}$. The choice of resistive load in this study is intended so that the harmonic current distortion that occurs at the current load and the current stator windings is purely caused by ELC. Harmonic measurements are performed on ELC input current $I_{\mathrm{ELCh}}$, stator windings current $I_{\mathrm{sh}}$, consumer load current $I_{\mathrm{Lh}}$, and PCC voltage $V_{\text {PCCh }}$ using CA 8220 Power Analyzer, as shown by the circuit in Figure 4.

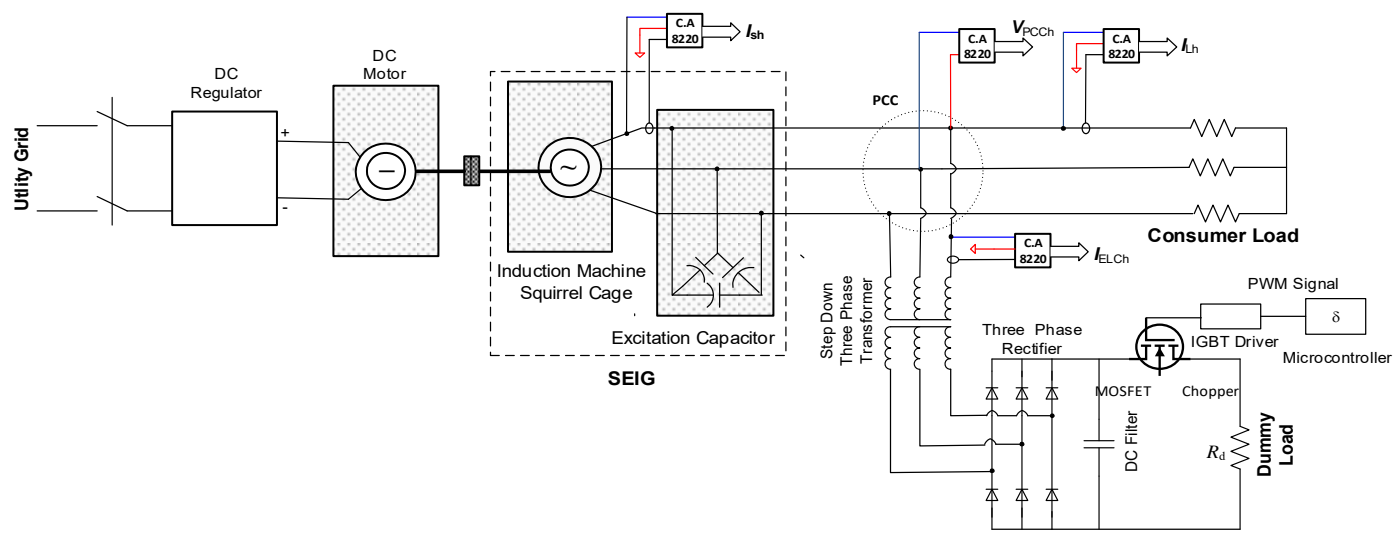

a. SEIG with ELC

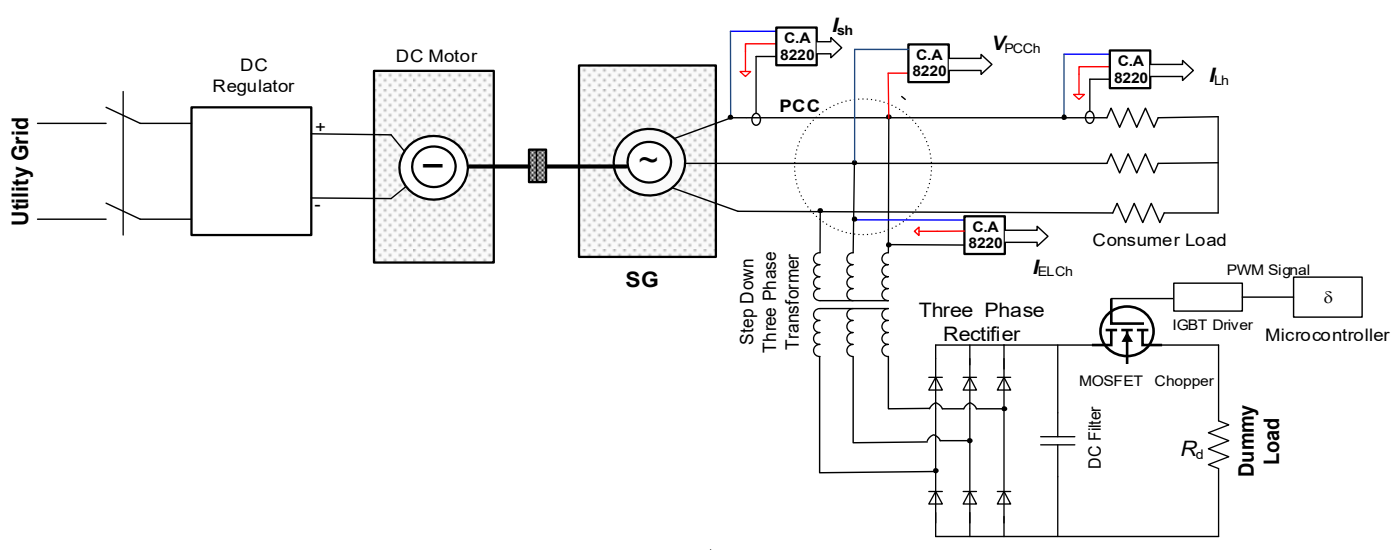

b. SG with ELC

Figure 4. Experiment circuit for SEIG with ELC and SG with ELC 
SEIG testing with ELC is carried out using an experimental circuit in Figure 4a. The first step, SEIG in conditions without ELC is loaded with 720 Watts. To reach line voltage to (220 2 ) Volt and a frequency of $(50 \pm 0.2) \mathrm{Hz}$, a starting drive speed of $1542 \mathrm{rpm}$ is needed and an excitation capacitor is $3 \times 10 \mu \mathrm{F}$ in the delta connection. Then the generator load is reduced to 675 Watts, so that the voltage and frequency of the generator will rise. To return the generator to the initial conditions, SEIG is connected to the ELC and the duty-cyclic is adjusted until the voltage and frequency are reached at the original value. Furthermore, the same method is done with the previous step to change the power from 600 Watts to 75 Watts. As long as the consumer load changes, the amount of consumer power and compensation power $\left(P_{\mathrm{L}}+P_{\mathrm{C}}\right)$ is kept constant, so the generator output power will also be constant. For each change in load power, ELC input current $I_{\mathrm{ELCh}}$, generator stator current $I_{\mathrm{sh}}$, load current $I_{\mathrm{Lh}}$, and PCC voltage $V_{\mathrm{PCCh}}$ are recorded using the CA 8220 Power Analyzer.

SG testing with ELC is done using an experiment circuit in Figure 4b. In the initial stage, SG was in SG condition without ELC, and was loaded with 720 Watts. To reach the line voltage to (380 \pm 2$)$ Volt line and $(50 \pm 0.2) \mathrm{Hz}$ frequency, then the initial driving speed of $1500 \mathrm{rpm}$ and field current is needed 1.1 Ampere. At this stage, the consumer load was varied the same as the SEIG's test. However, during changes in the load on the SG, the initial driving speed is kept constant at $1500 \mathrm{rpm}$.

\section{RESULTS AND DISCUSSION}

\subsection{ELC chacteristics on different generators}

Installation of ELC on SEIG and SG is intended to control the voltage and frequency of the generator during the variation of consumer load. In this system, the control of the generator output is carried out by ELC through adjustment of the compensation power $\left(P_{\mathrm{C}}\right)$ following the variation of the consumer load, according to (1). The adjustment of the compensation power is conducted by setting the power dissipated to the dummy load, according to (2). Power control that dissipated into the dummy load are carried out by setting the value of the duty cycle $(\delta)$ of the DC Chopper PWM by the Arduino Uno microcontroller. The results of testing the variation between duty cycle and power are dissipated to the dummy load of the ELC designed for both types of generators tested shown in Figure 5a. Power dissipased to the dummy load are straight-line with variations in duty cycles for the two different generators. But for the same duty cyle value, the power dissipated to the dummy load on SEIG is slightly larger than SG, especially for large duty cycle values.

Figure $5 \mathrm{~b}$ shows the test results of the duty cycle $(\delta)$ needed to maintain the generator output voltage at $(380 \pm 2)$ Volts and frequencies at $(50 \pm 0.2) \mathrm{Hz}$ during variations in consumer load power from 150 Watts to 675 Watts. During this test, the amount of active power load $\left(P_{\mathrm{L}}\right)$ and the compensasion power $\left(P_{\mathrm{C}}\right)$ is made constant. For the same consumer load power, the SG duty cycle $(\delta)$ is smaller than the setting for SEIG, as shown in Figure $5 b$.

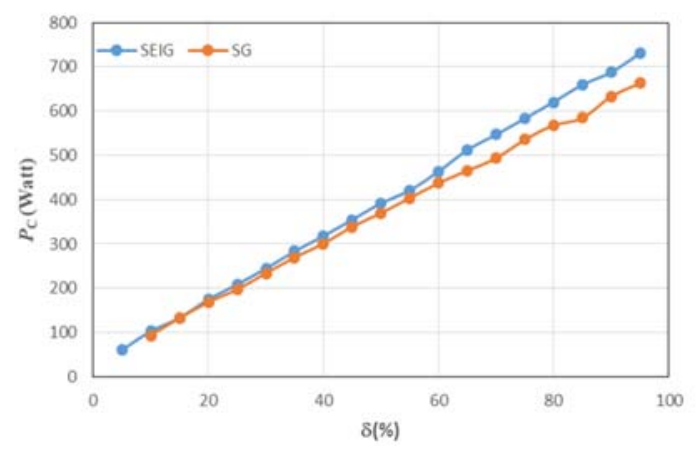

a. $P_{\mathrm{C}}$ versus $\delta$

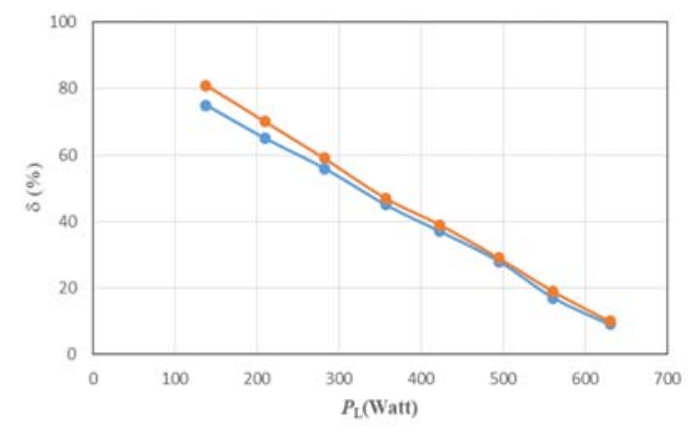

b. $\delta$ versus $P_{\mathrm{L}}$

Figure 5. ELC Characteristic for different generators

\subsection{Current harmonics generated by ELC on different generators}

Figure 6 shows the results of testing the waveform and harmonic spectrum of the current generated by the ELC on the SEIG which is loaded with 375 Watts. As shown in Figure 6, the installation of ELCs on SEIG will result in considerable harmonic current generation, especially harmonics for orders 5, 7, 9, 11 and 13, with Total Harmonic Distortion Current $\left(\mathrm{THD}_{\mathrm{I}}\right)$ reaching $72.6 \%$. While the same ELC installation on SG 
for the consumer load of 375 Watt will generate harmonic current with a smaller THD , as shown in Figure 7. In this Figure, it is shown that the current $\mathrm{THD}_{\mathrm{I}}$ generated by the ELC in SG only reached $26.2 \%$, with the largest IHD on the 5 th order.

Figure 8 shows the results of testing for the trend of changing the THD I value of the current harmonic generated by ELC during the variation of consumer load for each use of SEIG and SG. As shown by this Figure, $\mathrm{THD}_{\mathrm{I}}$ from harmonic currents generated by ELC on SEIG varies from 52.1\% at the consumer load of 150 Watt to $100.5 \%$ at the consumer load of 675 Watt, while for SG it varies from $19.1 \%$ at the consumer load of 150 Watt to $42.4 \%$ at the consumer load of 675 Watt. For both types of generators tested, an increase in the consumer load has caused an increase in $\mathrm{THD}_{\mathrm{I}}$. This is because the increase in consumer load reduces the value of duty cyle, which causes an increase in Crest Factor (CF). In addition, the THD I value of the ELC current on $\mathrm{SG}$ is smaller than the THDI value of the ELC current on SEIG. It is because in the SG equivalent circuit contains a synchronous reactance which can reduce high-order harmonic currents.

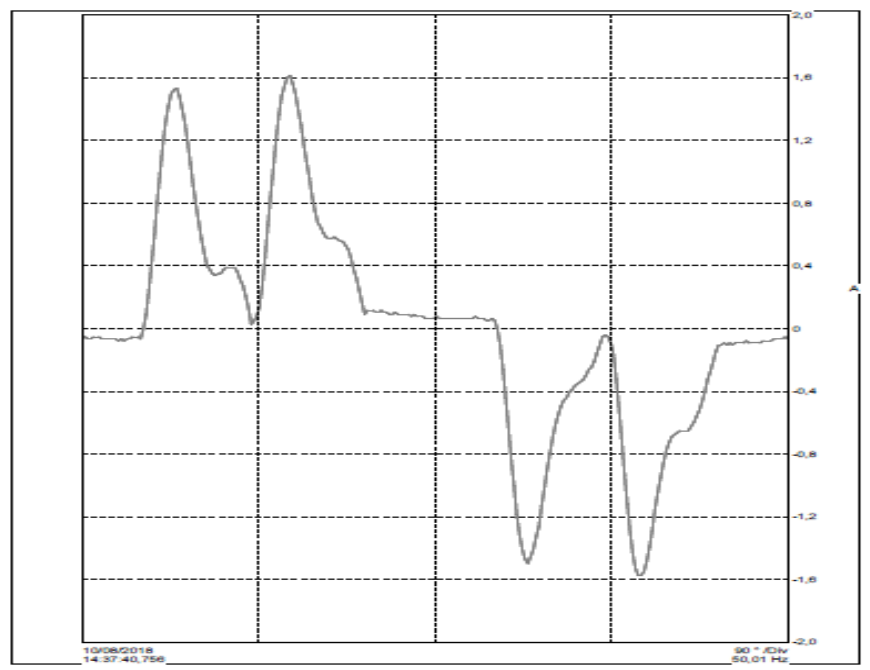

a. Waveform

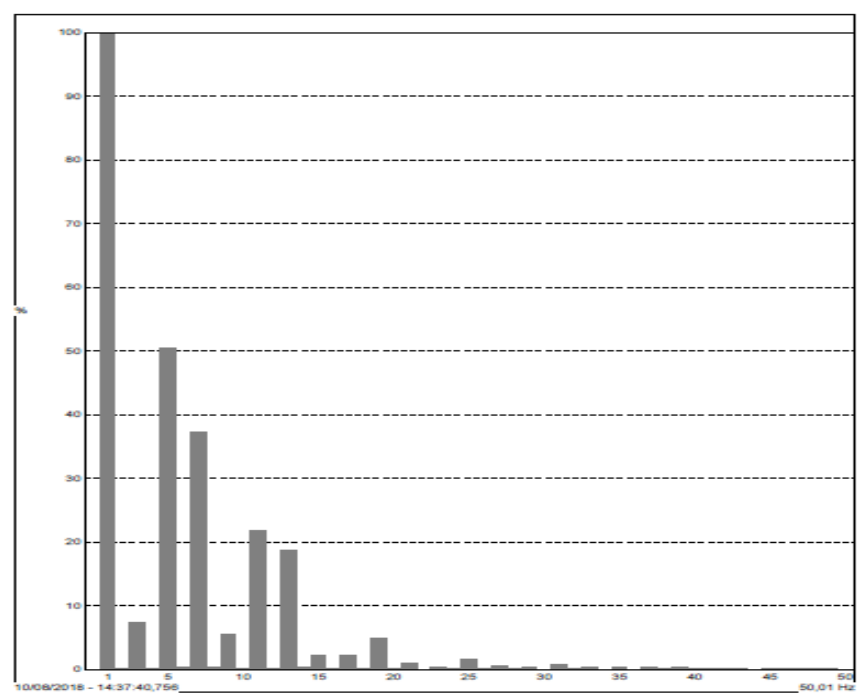

b. Harmonic spectrum

Figure 6. The testing results of the waveform and harmonic spectrum of the current generated by the ELC on the SEIG at the consumer load of 375 watt 


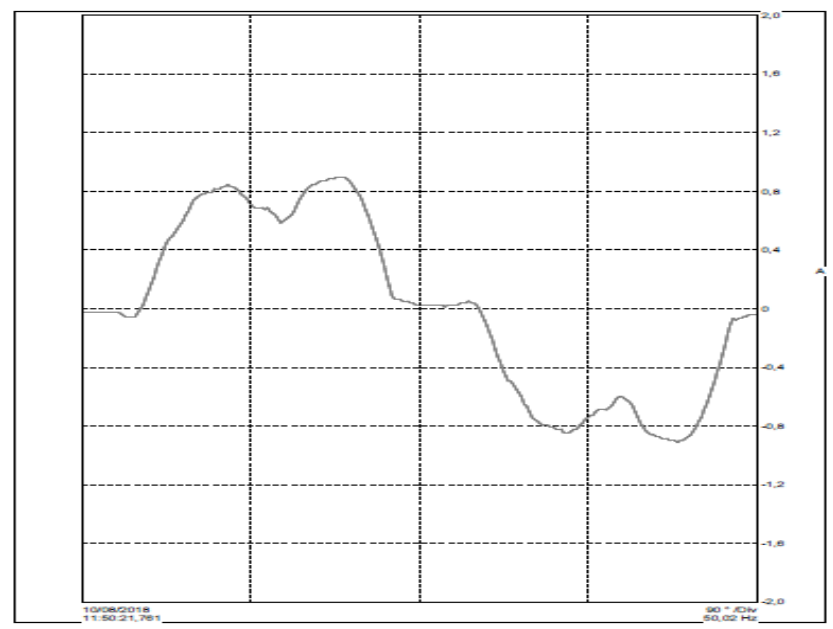

a. Waveform

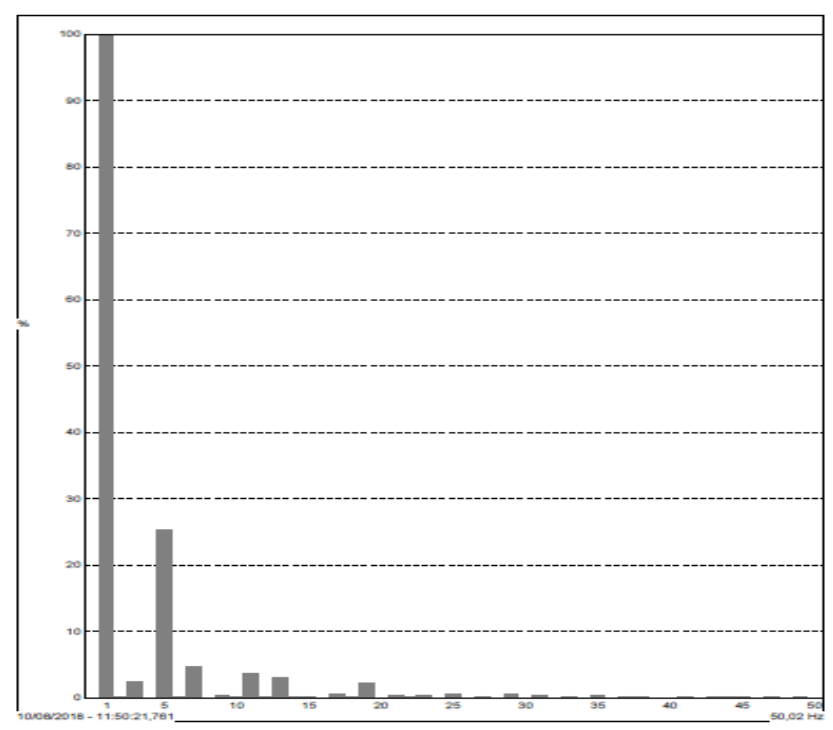

b. Harmonic spectrum

Figure 7. The testing results of the waveform and harmonic spectrum of the current generated by the ELC on the SG at the consumer load of 375 watt

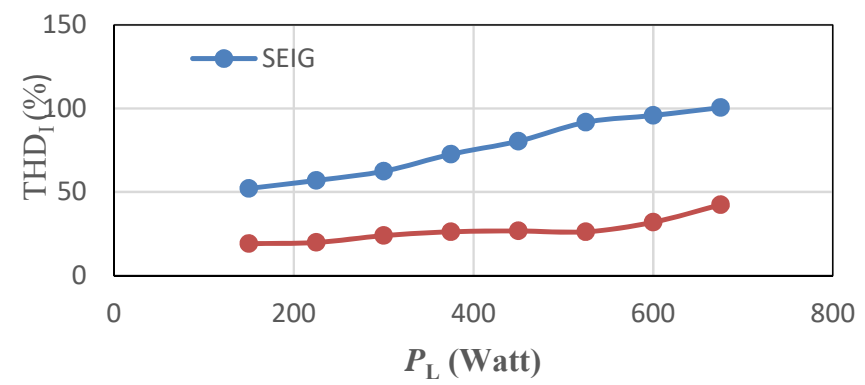

Figure 8. The results of testing for the trend of changing the $\mathrm{THD}_{\mathrm{I}}$ value of ELC current during the variation of consumer load for SEIG and SG 


\subsection{Harmonic distortion response in stator current for different generators type}

The recording results of waveform and harmonic parameters of stator current at SEIG for the consumer load of 375 Watt are shown in Figure 8. As shown this Figure, installation of ELC on SEIG has caused an increase in harmonic distortion in the stator current, with the THDI load current reaching $10.8 \%$. Whereas the installation of ELC on SG has resulted in an increase in harmonic distortion in the larger stator current, as shown in Figure 9. In this generator, the THDI stator current reaches $12.1 \%$.

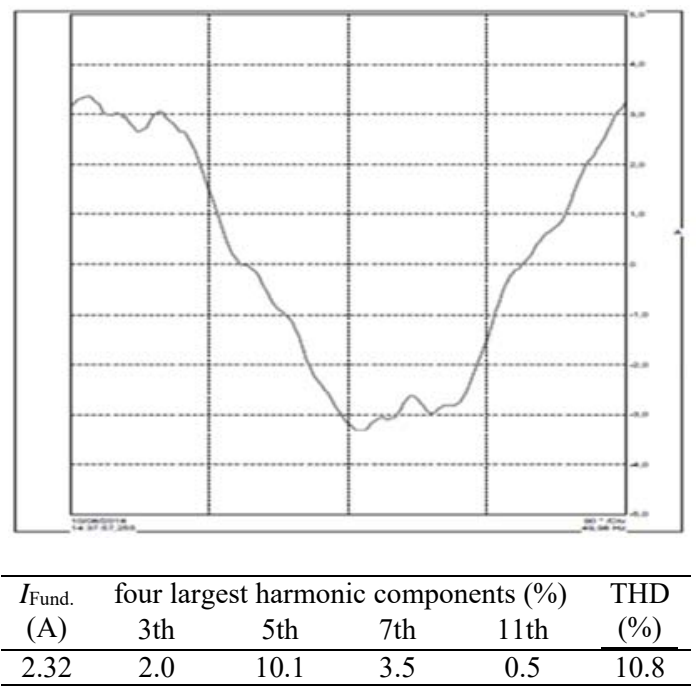

a. SEIG with ELC

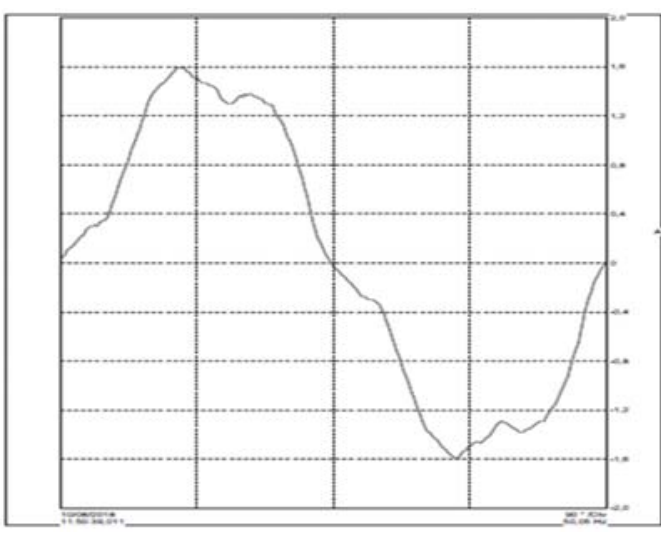

\begin{tabular}{cccccc}
\hline$I_{\text {Fund }}$ & \multicolumn{4}{c}{ four largest harmonic components (\%) } & THD \\
$(\mathrm{A})$ & 3th & 5th & 7th & 11th & (\%) \\
\hline 1.08 & 2.6 & 11.7 & 1.4 & 1.1 & 12.1 \\
\hline
\end{tabular}

b. SG with ELC

Figure 9. The testing results of the waveform and harmoncic parameters of the stator windings current on the SEIG and SG at the consumen load of 375 watt

Figure 10 shows the results of testing for the trend of changing the THDI value of the stator current during the variation of consumer load for each use of SEIG and SG. As shown by this Figure, THDI from the stator current on SEIG varies from $12.5 \%$ at the consumer load of 150 Watt to $3.9 \%$ at the consumer load of 675 Watt, while for SG it varies from $19.3 \%$ at the consumer load of 150 Watt to $6 \%$ at the consumer load of 675 Watt. For both types of generators tested, an increase in the consumer load has caused an decrease in THDI. It is mainly due to an increase in consumer load which will cause the ELC current composition to be contained in the stator current to decrease. This is mainly due to an increase in the consumer load will cause the composition of the ELC current contained in the stator current to decrease. In addition, the average value of THDI in the stator currents at SEIG is smaller than the THDI value in the stator currents at SG. This is possible because the SEIG terminal is connected in series with the excitation capacitor, which can block the high order harmonic current flowing into the stator windings.

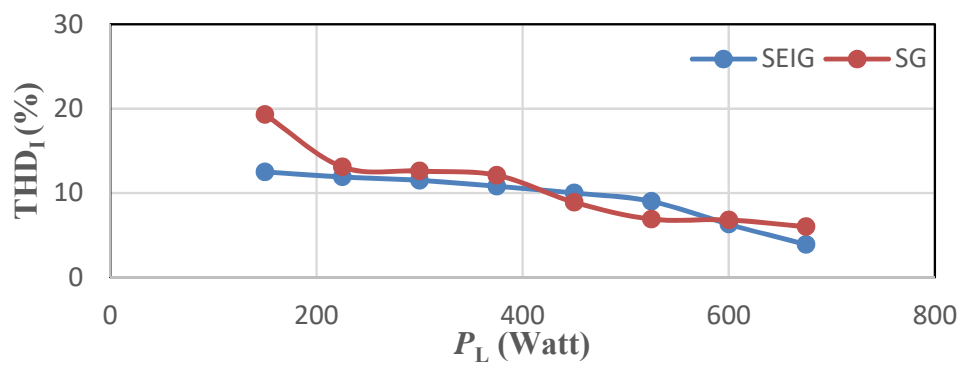

Figure 10. The results of testing for the trend of changing the $\mathrm{THD}_{\mathrm{I}}$ value of ELC stator current during the variation of consumer load for SEIG and SG 


\subsection{Harmonic distortions response in PCC voltages for different generators type}

Figure 11a shows the recording results of waveforms and harmonic parameters for PCC voltage on SEIG at consumer load of 375 Watt. As shown by Figure 11a, installation of ELC on SEIG has caused an increase in harmonic distortion at PCC voltage, with a $\mathrm{THD}_{\mathrm{V}}$ value of voltage reaching $5.8 \%$. Meanwhile, the installation of ELC on SG with the same consumer load has led to an increase in $\mathrm{THD}_{\mathrm{V}}$ value which is greater to $11.4 \%$, as shown in Figure $11 \mathrm{~b}$. This is mainly due to the $\mathrm{THD}_{\mathrm{I}}$ average value of the stator current on $\mathrm{SG}$ is greater than that of SEIG, so the voltage drop due to harmonic current in the SG stator windings becomes larger.

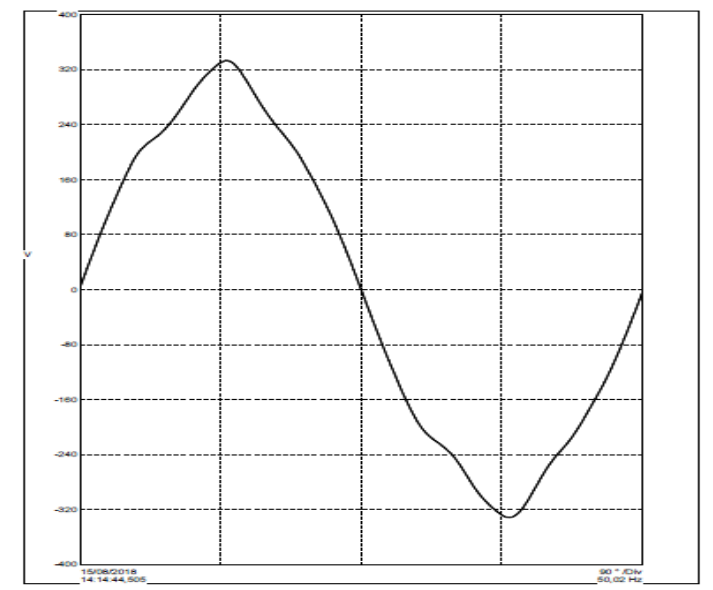

\begin{tabular}{cccccc}
\hline $\begin{array}{c}V_{\text {Fund. }} \\
\text { (V) }\end{array}$ & \multicolumn{4}{c}{ four largest harmonic components (\%) } & THD \\
& 3th & 5 th & 7th & 11 th & (\%) \\
\hline 219.7 & 1.2 & 5.1 & 2.4 & 0.6 & 5.8 \\
\hline
\end{tabular}

a. SEIG with ELC

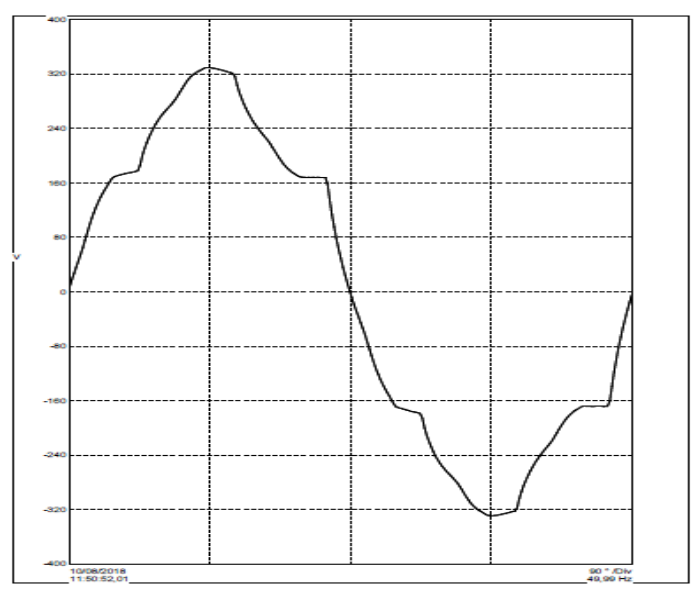

\begin{tabular}{cccccc}
\hline $\begin{array}{c}V_{\text {Fund }} \\
\text { (V) }\end{array}$ & \multicolumn{4}{c}{ four largest harmonic components (\%) } & THD \\
& 3th & 5th & 7th & 11th & (\%) \\
\hline 221.8 & 2.2 & 10.0 & 4.1 & 2.3 & 11.4 \\
\hline
\end{tabular}

b. SG with ELC

Figure 11. The testing results of the waveform and harmonic parameters of the PCC voltage on the SEIG and SG at the consumer load of 375 watt

The results of testing for the trend of changing the THD v value of the PCC voltage during the variation of consumer load for each use of SEIG and SG is shown in Figure 12. As shown by this Figure, THD $_{v}$ of the PCC voltage on SEIG varies from $1.5 \%$ at the consumer load of 675 Watt to $6.3 \%$ at the consumer load of 150 Watt, while for SG it varies from $4.8 \%$ at the consumer load of 675 Watt to $17.3 \%$ at the consumer load of 150 Watt. For both types of generators tested, an increase in the consumer load has caused an decrease in $\mathrm{THD}_{\mathrm{V}}$. The $\mathrm{THD}_{\mathrm{V}}$ value of PCC voltage at SEIG is smaller than the THDV value of PCC voltage at SG. This is mainly caused by the voltage drop due to harmonics in the stator windings on SEIG smaller than in the sator windings on SG.

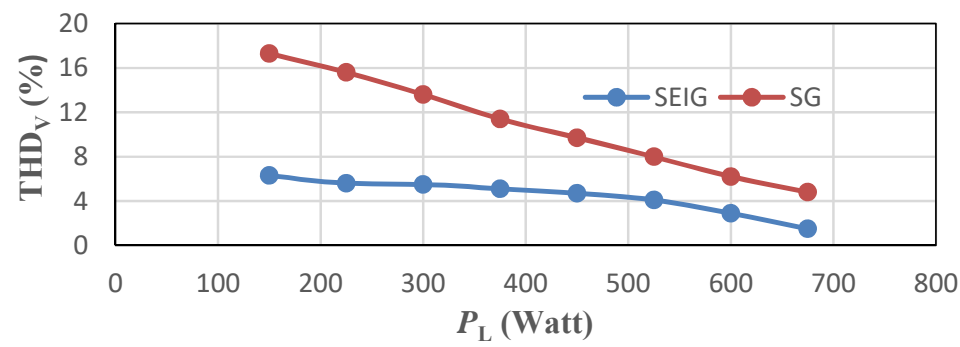

Figure 12. The results of testing for the trend of changing the $\mathrm{THD}_{\mathrm{V}}$ value of $\mathrm{PCC}$ voltage during the variation of consumer load for SEIG and SG 


\subsection{Harmonic distortions response in the consumer load current for different generators type}

The results of recording for the trend of changing the $\mathrm{THD}_{\mathrm{I}}$ value of the consumer load current during the variation of consumer load for each use of SEIG and SG at consumer load of 375 Watt is shown in Figure 13a \& Figure 13b. As shown by Figure 13a, installation of ELC on SEIG has caused an increase in harmonic distortion in the consumer load current, with the $\mathrm{THD}_{\mathrm{I}}$ consumer load current reaching $6 \%$. While, the installation of ELC on SG has resulted in an increase in harmonic distortion in the larger consumer load current, as shown in Figure 13b. In this generator, the $\mathrm{THD}_{\mathrm{I}}$ consumer load current reaches $11.3 \%$.

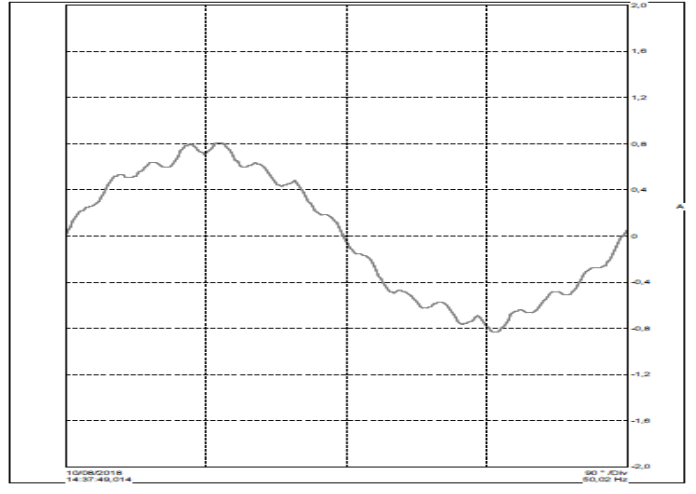

\begin{tabular}{cccccc}
\hline $\begin{array}{c}\text { IFund } \\
\text { (A) }\end{array}$ & \multicolumn{4}{c}{ four largest harmonic components (\%) } & THD \\
& 3th & 5th & 7th & 11th & (\%) \\
\hline 0.54 & 3.4 & 5.1 & 2.5 & 0.5 & 6.0 \\
\hline
\end{tabular}

a. SEIG wih ELC

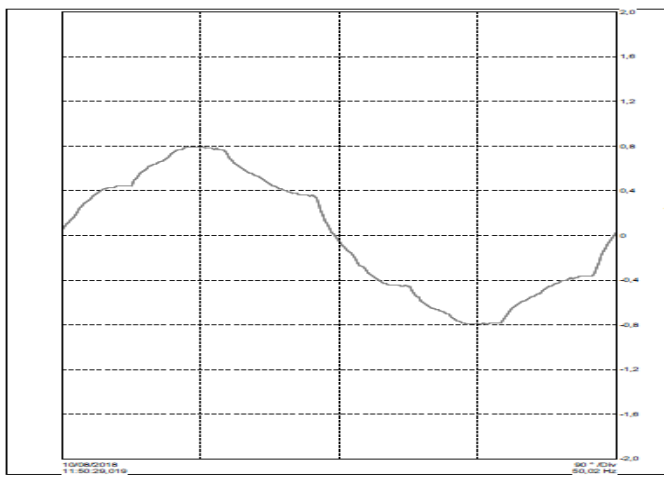

\begin{tabular}{cccccc}
\hline IFund & \multicolumn{4}{c}{ four largest harmonic components (\%) } & THD \\
(A) & 5th & 7th & 11th & 13th & (\%) \\
\hline 0,54 & 9.8 & 3.2 & 2.4 & 2.2 & 11.3 \\
\hline
\end{tabular}

b. SG with ELC

Figure 13. The recording results of the waveform and harmonic parameters for the consumer load current on the SEIG at the consumer load of 375 Watt

Overall the test results from the change in the $\mathrm{THD}_{\mathrm{I}}$ value of the consumer load current to the variation of consumer load for SEIG and SG are shown in Figure 14. As shown this Figure, THD value of the consumer load current on SEIG varies from $2.9 \%$ at the consumer load of 675 Watt to $6.2 \%$ at the consumer load of 150 Watt, while for SG it varies from $4.4 \%$ at the consumer load of 675 Watt to $17.3 \%$ at the consumer load of 150 Watt. For both types of generators tested, an increase in the consumer load has caused an decrease in THD . The THD I value of the consumer load current at SEIG is smaller than the THD I value of the consumer load current at SG. It can be understood that the pattern of changing the $\mathrm{THD}_{\mathrm{I}}$ value from the consumer load current will be the same as the pattern of changes in the $\mathrm{THD}_{\mathrm{V}}$ value from the PCC voltage.

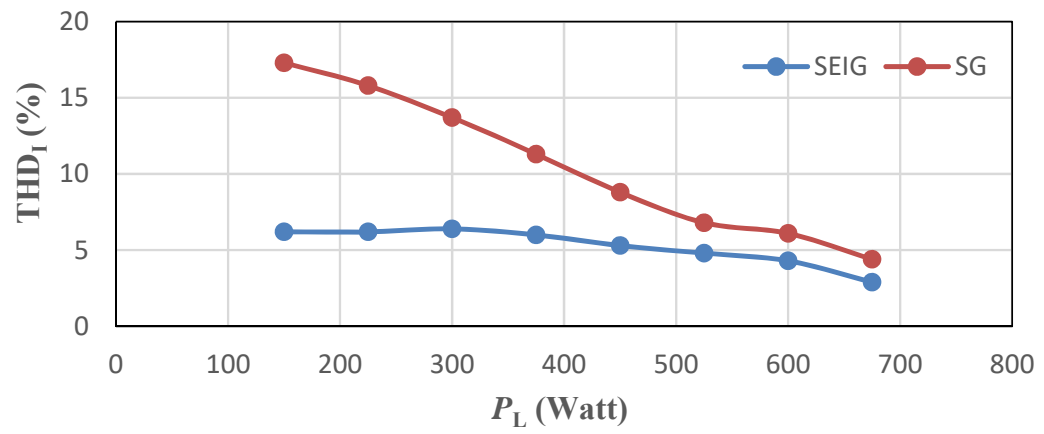

Figure 14. The results of testing for the trend of changing the $\mathrm{THD}_{\mathrm{i}}$ value of consumer load current during the variation of consumer load for SEIG and SG 


\section{CONCLUSION}

In this paper, it has been successful compared the harmonic distortion response due to the installation of ELC on SEIG and SG. THDI value of harmonic current generated by ELC on SEIG is always greater than THDI value of harmonic current generated by ELC on SG. Even though, the harmonic distortion that most influences the generator performance for SEIG and SG applications is the harmonic distortion in the stator current, PCC voltage, and consumer load current. The THDI value of the stator current from SEIG is on average smaller than the THDI value of the stator current from SG. Similarly, the THDV value of PCC voltage and the THDI value of the current consumer load current from SEIG are always smaller than the THD value of the PCC voltage and the THDI value of the consumer load current from SEIG. Overall, the effects of harmonic distortions due to installation of ELCs developed, on SEIG is still within the permitted limits. Meanwhile, due to the installation of ELC on the SG, the harmonic distortion reduction is needed at the generator output.

\section{ACKNOWLEDGEMENTS}

Author would like thanks to Andalas University for the financial support this work, through PDUPT Funding (No. 01/UN.16.17/PP.PDUPT.EET/LPPM/2018)

\section{REFERENCES}

[1] Bhim Singh, S. S. Murthy, and Sushma Gupta, "Analysis and Design of Electronic Load Controller for Self-Excited Induction Generators," IEEE Transactions on Energy Conversion, 21(1): 285-293, 2006.

[2] B. Singh, S.S. Murthy, and S. Gupta, "Analysis and implementation an electronic load controller for a self-excited induction generator," IEE Proc-Gener.Transm. Distrib, 151(1): 51-60, 2004.

[3] Nan Win Aung, and Aung Ze Ya, "Design Calculation and Control System Simulation of a Microcontroller Based on Electronic Load Controller for Stand-Alone Micro-Hydro Power Plant," International Conference Science and Engineering. 2014.

[4] Refdinal Nazir, Krismadinata, and Rizka Amalia, "The Camparison of Harmonic Distortion Self-Excited Induction Generator with Isolated Synchronous Generator under Non-linear Loads," International Journal of Power Electronics and Drive System (IJPEDS), 6(4): 759-771, 2015.

[5] Refdinal Nazir, Andi Pawawoi, Farah Ramadhani, "The Energy Storage System on the Batteries with PWM Method to Regulate the Output Voltage of SEIG," Proceeding of International Conference on Electrical Power and Energy Systems. Nedherland. 2011.

[6] Refdinal Nazir, Krismadinata, and Rizka Amalia, "Harmonic Effect Analysis of Electronic Load Controller on SelfExcited Induction Generator (SEIG) Operation," Indonesian Journal of Electrical Engineering and Computer Science. 8(2): 273-280, 2017.

[7] IEEE Power Engineering Society \& IEEE Industry Applications Society, "IEEE Recommended Practices and Requirements for Harmonic Control in Electrical Power Systems," The Institute of Electrical and Electronics Engineer Inc. 2004

[8] Nikunj Shah, "Harmonics in Power System: Causes, Effect, and Control," Siemen Industry Inc. 2013.

[9] Predrag Pejovi'c., "Three-Phase Diode Rectifier with Low Harmonics," Springer. 2007.

Int J Pow Elec \& Dri Syst, Vol. 10, No. 1, March 2019: $104-116$ 